\title{
Dengue Infection: Frequently Asked Questions by People in the Province of Aklan, Philippines
}

\author{
Benie T. Constantino IH, ART (CSMLS); I, SH (ASCP) ${ }^{1}$, Dr Makarius Tel Aviv C. Dela Cruz III ${ }^{2 *}$ \\ ${ }^{1}$ Guelph, Ontario, Numancia, Aklan, Philippines, Canada. \\ ${ }^{2}$ Municipal Health Officer, Kalibo, Aklan, Philippines.
}

*Corresponding Author: Dr Makarius Tel Aviv C. Dela Cruz III, Municipal Health Officer, Kalibo, Aklan, Philippines.

Received date: June 16, 2021; Accepted date: June 29, 2021; Published date: July 02, 2021

Citation: Benie T. Constantino, M T A C DelaCruz. (2021) Dengue Infection: Frequently Asked Questions by People in the Province of Aklan, Philippines. Journal of Clinical and Laboratory Research. 3(2); DOI:10.31579/2768-0487/032

Copyright: (92021 Makarius Tel Aviv C. Dela Cruz III. This is an open-access article distributed under the terms of the Creative Commons Attribution License, which permits unrestricted use, distribution, and reproduction in any medium, provided the original author and source are credited.

\begin{abstract}
Dengue virus is the most common mosquito borne viral disease in humans, and poses a major challenge to global public health services. Infection can be caused by any of the 4 DENV serotypes, transmitted by female Aedes aegypti mosquitoes. Presenting features may vary from a mild self-limiting febrile illness to life-threatening symptoms of bleeding, organ impairment, and plasma leakage leading to shock. Early diagnosis and monitoring are critical to reduce mortality, especially in the context of the COVID-19 pandemic. Laboratory tests, such as the serological detection of either antigen or antibodies are useful in the diagnosis. Currently, although a vaccine for DENV is available, it remains a challenge to develop an effective vaccine against 4 discrete serotypes and antiviral drugs effective in reducing morbidity or improving disease outcome.

Keywords: dengue virus; dengue hemorrhagic fever; aedes aegypti mosquitoes; secondary infection; antibody dependent enhancement
\end{abstract}

\section{Introduction}

Dengue virus (DENV) is an arbovirus which is spread to humans by the bite of female Aedes aegypti mosquitoes (AMs) [1]. Four serotypes (DENV 1 to 4) had been distinguished, all of which can cause the full spectrum of the disease [2]. Dengue infection has recently become a major public health problem in the Philippines, [3] particularly in the urban and semi-urban areas of the province of Aklan. More than 100 countries are endemic, primarily affecting 50 million people annually and around 2.5 billion inhabitants are at risk of DENV infection [4-6].

In the early 1950's, severe dengue infection was recognized in the Philippines, [7, 8] and primarily described as hemorrhagic fever or infectious acute thrombocytopenic purpura $[9,10]$. Others described the same illness as Philippines and Bangkok hemorrhagic fever initially, but now it is commonly known as dengue hemorrhagic fever (DHF) [11, 12]. Since the first outbreak of DHF in the Philippines in 1956, [13] dengue epidemics have occurred in the country every 3 to 5 years, $[14,15]$ and cases spiked most recently in 2019 [16]. In Aklan, an estimated 5749 cases and 23 deaths were reported in the same year 2019. During the 1980s, dengue infection has been hyperendemic and a leading cause of childhood hospitalization in the Philippines $[17,18]$.
The contributing factors for the widespread expansion and increasing dengue incidences, include the rapid urbanization, poor sanitation facilities, ineffective vector control, climate change, shipping and viremic travelers, and increased international travel [19-21]. Increased travel and trade over the past half century have contributed to the global spread of dengue diseases $[8,22,23]$. Moreover, the globalization of trade and waste management, especially the trade of tires from used vehicles, promotes the dispersal of eggs and immature forms of dengue to other countries [24]. The increased urbanization and subsequent larger population density have led to enhanced vector breeding sites and contact between humans and vectors, and thus, sustained endemicity. Endemicity can, therefore, occur annually during the rainy season which is an optimal period for mosquito breeding.

Although the majority of dengue infections are asymptomatic, a wide variety of clinical symptoms, ranging from mild febrile illness known as dengue fever, to the severe forms of the disease called DHF can be observed. The latter is characterized by prominent hemorrhagic manifestations with thrombocytopenia, coagulopathy, and plasma leakage, which may progress to hypovolemic shock known as dengue shock syndrome (DSS) and is associated with high mortality rate [3,25]. Understanding the mechanism underlying the occurrence of shock is crucial for the development of treatment strategy to improve patient care. 
Currently, the diagnosis is largely clinical, and the treatment remains supportive and symptomatic with particular emphasis on fluid replacement, better clinical management, and the use of analgesics and antipyretics with balance nursing care [26, 27].

Like other viruses, the DENV is a microscopic structure that can only replicate and proliferate inside a living cell. Many questions, however, remain regarding DENV research. This review explores these research questions, and other commonly asked questions/topics about dengue infection.

\section{Dengue Virus}

DENV belongs to the family Flaviviridae, genus Flavivirus, and is transmitted to humans by female AMs. Four serotypes of the virus have been identified: DENV-1, $-2,-3$, and -4 . AM is the primary vector of several viruses including yellow fever virus, dengue virus, chikungunya virus, and Zika virus [1].

DENV Genome. DENV is a single-stranded, positive-sense RNA genome (Figure 1) which encodes 10 proteins. Three of these are structural proteins: capsid (C), membrane (M) protein, and envelope (E) that form the coat of the virus and deliver the RNA to target cells. Seven are nonstructural (NS) proteins: NS1, NS2A, NS2B, NS3, NS4A, NS4B, and NS5 that orchestrate the production of new viruses once the virus gets inside the cell $[28,29]$. The M protein is the mature form of the premembrane protein. Many viruses go through a maturation step before being transmitted to another host. The maturation process of DENV is directed by the proteolytic cleavage of the precursor M protein, turning inert virus into infectious particles [30].

The nonstructural proteins are involved in viral assembly, translation, transcription, and replication [6,31]. Notably, NS1 is expressed both on the surface of infected cells without forming part of the virion and on the serum [32]. NS3 is a protease and plays a role in viral RNA replication, acting as an RNA helicase. NS5 is the RNA polymerase in charge of viral replication [32].

DENV Structure. DENV is a round spherical enveloped, with a diameter of approximately $50 \mathrm{~nm}$ (Figure 1) [33]. The core of the DENV is the nucleocapsid, a structure that is made of the viral genome along with $\mathrm{C}$ proteins. The nucleocapsid is covered by a viral envelope, a lipid bilayer that is taken from the membrane of infected human cell. Attached in the viral envelope are 180 copies of the $\mathrm{E}$ and $\mathrm{M}$ proteins that span through the lipid bilayer. These proteins bear the virus neutralization epitope (antigenic determinant) that is responsible for virus attachment to receptor, endocytosis, and uncoating and fusion of the virus envelope with the target cell membrane, leading to the entry of virus into human cells and the viral replication [34].

DENV Replication (Life Cycle). DENV, like other viruses, thrive on replication not only for its existence, but also for the spreading of infection to others. The process of viral replication is shown in Figure 2. Replication begins when virus attaches to the surface of a host cell receptor, and enters the cell by a process called receptor-mediated endocytosis $[2,32]$. The virus is then endocytosed, the cell's membrane folds around the virus forming a pouch called endosome. Acidification of the endosome leads to the low $\mathrm{pH}$-induced conformational changes in the envelope protein allowing the virus to fuse with the endosomal membrane causing the release of nucleocapsid into the cytoplasm of the cell. In the cytoplasm, the nucleocapsid opens to uncoat the viral genome. The viral RNA then hijack the host cell's biosynthetic machinery to replicate the viral RNA genome and viral proteins. After maturing, the newly synthesized DENV are released via exocytosis and go on to infect other host cells [2].

After its injection into the skin, DENV undergo initial round of replication and multiplication in local Langerhans dendritic cells (LDCs) and keratinocytes $[1,35]$. Infected LDCs migrate to lymph nodes spreading infection to monocytes and macrophages. The lymphatic system then plays a key role in the ensuing viremia which develops within 24 hours. The virus subsequently spreads to other organs such as the spleen, liver, and bone marrow. The replication efficiency of DENV in dendritic cells, monocytes, macrophages as well as in the endothelial cells, bone marrow stromal cells, and hepatocytes, collectively determine not only the viral load in the blood which represents risk factor for severe disease development, but also the production of immune mediators, including cytokines, chemokines, interferons, and TNF that influence the extent, type, and duration of humoral and cellular responses to virus infections [36]. These mediators affect hemostatic system of the body.

DENV Receptors. Specific receptors for DENV have not been identified definitely, but may include heparan sulfate and lectins, the adhesion molecule of dendritic cells, the mannose receptor of macrophages, the lipopolysaccharide receptor, the heat-shock proteins 70 and 90, and the AXL receptors also called Tyroxine Kinase receptors [34]. The AXL receptors are predominantly expresssed by macrophages and are expressed also by the cells of the vascular, nervous, reproductive and immune systems. This suggests that DENV does not use a specific receptor for its entry into the cell, but recognizes and binds to diverse molecules thereby infecting a variety of cell types. However, pathological studies identified splenic and lymph node, monocytes, macrophages, and dendritic cells as major targets of DENV infection [34].

DENV Intrinsic Incubation and Infectious Period. Once inoculated into a human host, DENV has an incubation period of 4 to 7 days, range of 3 to 14 days (intrinsic incubation period). Persons with DENV can transmit the viruses to an AM one day before the onset of the febrile period and remain infectious for the subsequent 4 to 5 days and even up to 12 days.

DENV Mode of Transmission to Humans. The DENV are transmitted to humans by the bite of an infected female AM (vector) [37]. Although mosquito bites are the common means of transmitting the DENV, it can also be transmitted through contaminated blood transfusion, needle stick incidents, or organ transplants. An infected mother can also pass the virus to her unborn baby [38]. Humans serve as the primary reservoir for dengue, although certain nonhuman primates in Asia and Africa also serve as hosts, though they do not develop DHF. AMs acquire the virus when they feed on infected symptomatic or asymptomatic persons (carrier). Following a carrier bite, AMs become infectious after 8 to 12 days of viral replication in their salivary glands (extrinsic incubation period). They remain infected for the rest of their life. While male mosquitoes have a shorter life span of approximately 10 days, a female adult mosquito typically lives for 21 days, but lifespan can range from 15 to 65 days [37].

DENV Serotypes. Dengue infections are caused by 4 closely related serotypes named DENV $-1,-2,-3$, and -4 , although a fifth one called Aedes Albopictus has been identified. They are called serotypes as each has different interactions with the antibodies (Abs) in human blood serum [33]. These 4 viruses are almost similar, sharing approximately $65 \%$ of their genome, and even with some mild genetic variation, infection with each of the dengue serotypes can cause the same full spectrum of clinical disease. Because there are 4 strains of DENV, a person during a lifetime living in a dengue-endemic area may have face 4 dengue infections [23]. A tertiary dengue infection can cause severe disease, but only rarely [39]. Thus, a need is clear to identify and distinguish the DENV serotype for heterotypic differentiation and clinical diagnosis and treatment.

\section{Dengue Infection}

Dengue infection includes dengue fever, DHF and DSS, and it develops after a person is bitten by a female AM carrying one of the four strains of DENV. DENV infection is responsible for the most significant mosquito- 
borne illness in the world today [40]. Between 50 and $75 \%$ of all infected people have very mild signs or symptoms of the disease or are asymptomatic, and approximately $5 \%$ or 1 in 20 DENV patients, progress to develop life-threatening severe dengue disease. When symptoms do occur, they usually begin 4 to 7 days after infection and may last up to 14 days [40].

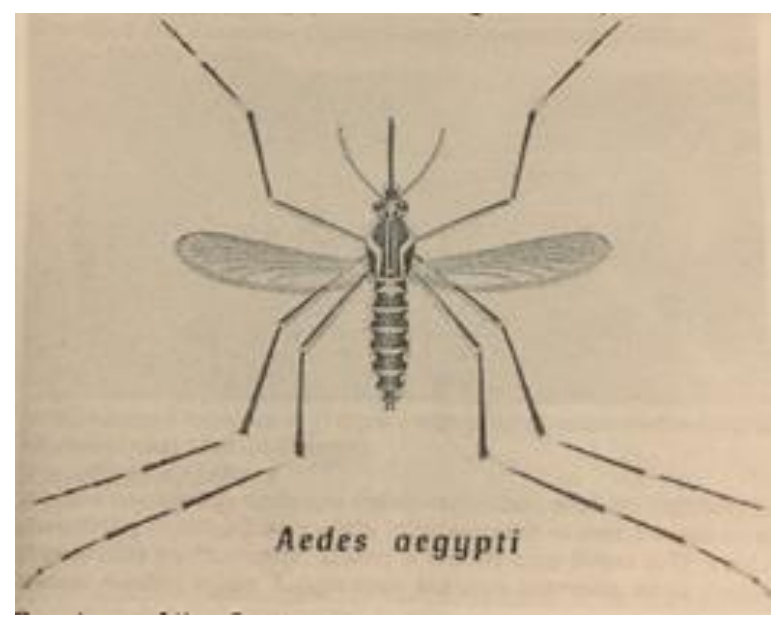

Figure 1: Dengue virus structure.

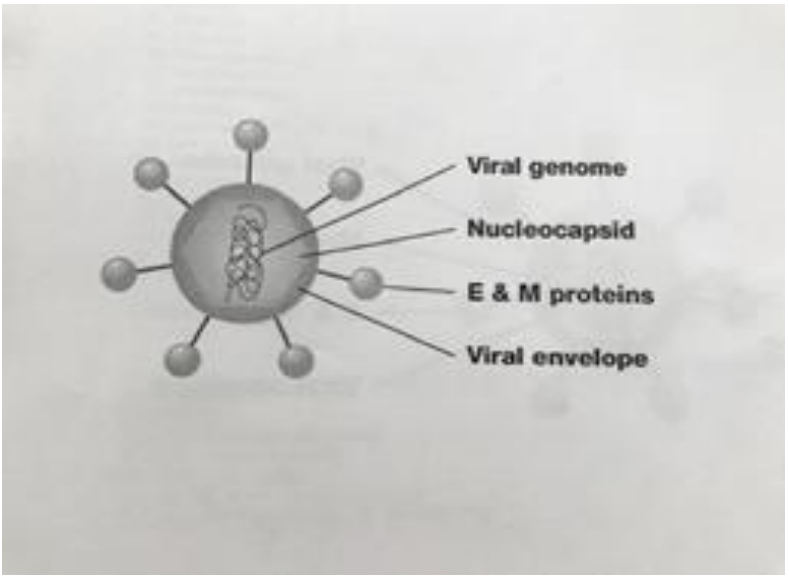

Figure 2: Aedes Aegypti Mosquito

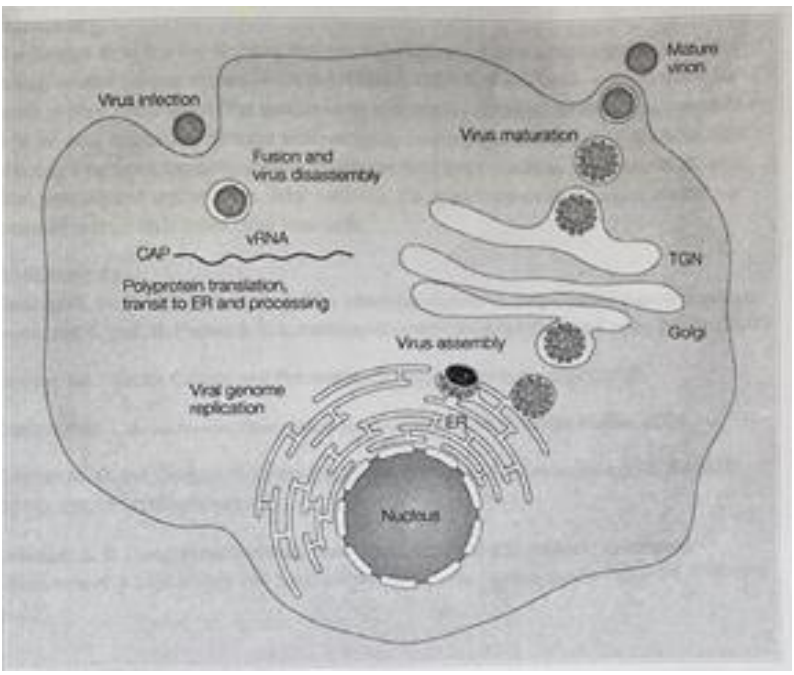

Figure 3: Dengue virus réplication 


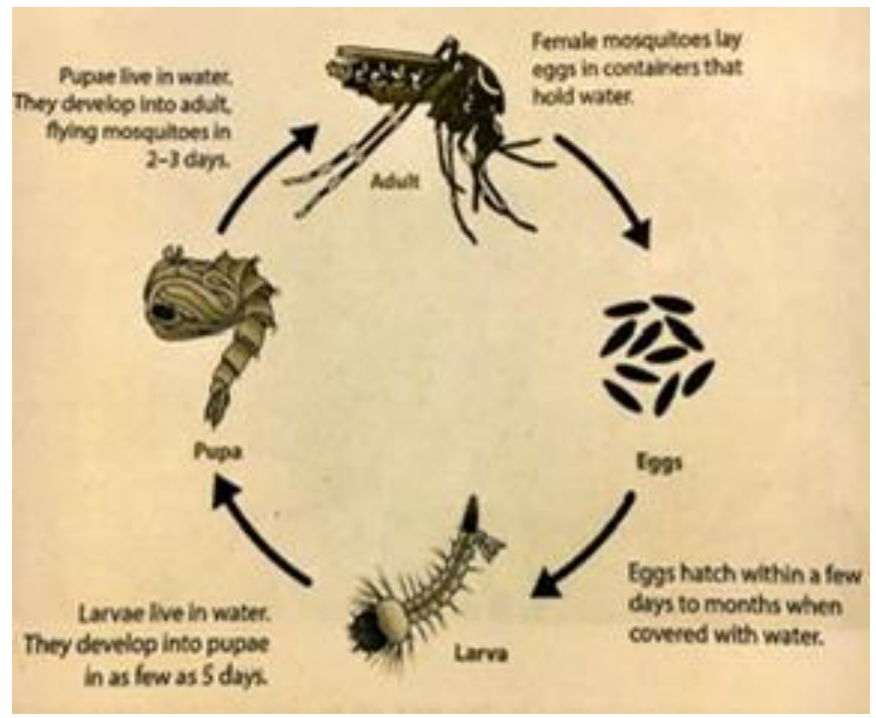

Figure 4: Life cycle Aedes Aegypti Mosquito

Dengue Fever Suspicions. Dengue fever should be suspected with sudden onset of high fever (and chills) accompanied by 2 or more other symptoms including severe headache mainly in the forehead, pain behind the eyes, severe pain in the muscles, joint, and bone, restless, nausea, vomiting, abdominal pain, swollen glands, mild bleeding, and skin rashes which appear 2 to 5 days after the onset of fever [41]. Although these symptoms are unlikely to occur simultaneously, a fever and minimum of 2 or 3 main symptoms, such as pain in the eyes, muscles, joint, or bone, and skin rashes can not only suspect dengue, but also differentiate it from other causes of fever. The severe bone and joint pain caused by dengue is why it is also called "break-bone fever" $[5,8]$.

DENV Infection Progression. Symptomatic illness typically follows 3 broadly identifiable phases: febrile, critical, and recovery [22, 42]. Appropriate diagnosis and evaluation of varying signs of progression to severe disease are critical for effective patient management.

\section{Febrile Phase (2-7 days)}

- Self-limiting condition with a rapid onset of high fever over $40^{\circ} \mathrm{C}$ for 2 to 7 days.

- Signs and symptoms include generalized pain, body ache, headache, nausea and vomiting, myalgia, arthralgia, retroorbital eye pain, and rash may occur in $50-80 \%$ of the infected people.

- Dehydration due to decreased fluid intake. Convulsion due to high fever. Mild hemorrhagic manifestations include petechia, bleeding gums, epistaxis, or a positive tourniquet test. Rarely, severe hemorrhage.

Many patients fully recovered after defervescence; however, some patients develop warning signs of progression to severe dengue, including severe abdominal pain, persistent vomiting, mucosal bleeding, rapid breathing, liver enlargement, lethargy, restlessness, plasma leakage, and progressive increase in hematocrit and decrease platelet counts. [42]. Despite these warning signs, consequential challenges remain in the clinical management of the disease because of the overlapping signs and symptoms in febrile and acute phase of the illness. Hence the need for a specially trained nurses and clinicians experienced with the effects and progression of the disease can save lives.

Critical Phase (1-2 days)
- $\quad$ Phase begins at defervescence from day 3 to 7 of illness, when temperature drops to $38^{\circ} \mathrm{C}$ and last for $24-48$ hours; patients either improve or deteriorate.

- Most patients clinically improve, but others show warning signs of progression to serious illness.

- Platelets drop markedly with simultaneous increased in hematocrit, both changes occur before onset of shock.

- Coagulopathy includes prolongation of INR/PT and partial thromboplastin time and reduced fibrinogen.

- Varying degrees and/or unrecognized severe plasma leakage or hemorrhage may lead to shock.

- Without appropriate fluid resuscitation, patients can deteriorate into profound shock.

- With prompt appropriate medical treatment, most patients recovered uneventfully and survived to be discharged from the hospital care [22].

Complications primarily affect the vascular system, and include coagulopathy sometimes accompanied by bleeding and organ impairment, and significant plasma leakage that may result in fatal DSS [44].

\section{Convalescence Phase (2-3 days)}

- Happens in the next 48 to 72 hours in which body fluids return to normal.

- Resolution of plasma leakage and hemorrhage.

- Stabilization of hemodynamic status and vital signs. Hematocrit stabilizes and the white cell count starts to rise, followed by recovery of platelet count.

The outcome of dengue infection depends on a delicate balance between unfavorable and favorable immune responses. The former enhancing the inflammatory and vascular permeability and severe dengue, whereas the latter providing the control of the level of viral spread and replication and viremia [22].

Biomarkers for Predicting Progression to Severe Dengue. 
Biomarker is a characteristic that can be measured and evaluated as an indicator/predictor of normal biological and/or pathogenic processes. Identification of markers for disease progression to more severe forms of disease have been a major interest in dengue research. The ability to recognize early a patient likely to progress to DHF remains challenging but would be an important step in improving clinical management in the context of the high pressure on ICUs. This could decrease unneeded hospitalization of milder cases and help prioritize or triage patients quickly when healthcare resources are limited [44].

Recently, a potential biomarker, such as C-reactive protein (CRP), for disease progression in dengue has been proposed. CRP is an acute-phase protein produced by the liver in response to inflammatory stimuli. It is not normally found in the blood of healthy people, but appears after injury, infection, or inflammation and disappears when the injury heals [43]. In patients with confirmed dengue, higher levels of CRP, with a CRP cutoff value of $30.1 \mathrm{mg} / \mathrm{L}$, range from 12.4 to $61.2 \mathrm{mg} / \mathrm{L}$ (100\% sensitivity and $76.3 \%$ specificity), measured in the first 3 days of illness could be a useful indicator for early risk prediction of severe dengue and may assist differentiating dengue from other diseases [43].

Aside from CRP, several potential biomarker predictors of severity include markers of endothelial activation and microvascular disruption, markers of dysregulation of the alternative complement pathway, the elevated levels of proinflammatory molecules such as IL-6 and sPLA2 and immunological cytokines which include IL-7, IL-8, IL-10, TNF $\alpha$, IFN $\gamma$ [44-47]. The elevated levels of cytokines in severe dengue make them an excellent predictor of severity of infection. Moreover, high levels of plasma dengue viral RNA load during defervescence [48], and high levels of DENV NS1 protein within 72 hours of illness onset may also serve an indicator [49]. NS1 antigen has been shown to cause disease pathogenesis by inducing cytokine production, vascular leak, and IL-10 production. Hematological markers, such as HCT and platelet count have been also considered as potential predictors [44].

All these indicators, in one way or another, help in identifying patients likely to progress to DHF.

Some of these biomarker parameters are relatively easy to measure and may form part of routine medical examinations. For example, HCT and platelet count, as part of CBC parameters, are routinely measured when $\mathrm{CBC}$ is requested. As markers, they may show good sensitivity but with poor specificity. Other tests may show good specificity but are relatively expensive to measure and limited to centers with specialist expertise [44].

Nonetheless, CRP determination is highly attractive option as a prognostic tool than other potential marker tests because of the cheap and readily available point-of-care test kits and its well-established use as a clinical test. Circulating CRP levels are considered an indicator of the level of ongoing inflammation [69]. Because the hallmark of severe dengue is excessive inflammation, elevated CRP levels in dengue may represent the degree or extent of inflammatory injuries that may influence clinical outcomes. Biomarkers may be used alone or in combination to assess disease state of an individual [69]. Obviously, these biomarkers are very important, as early detection could drastically reduce severe diseases and death.

High Risk for Dengue Hemorrhagic Fever. DENV pathogenesis remains a complex interplay between the virus, vector, and host, and their severity are modulated by multiple risk factors including:

- $\quad$ Age (infants, small children, older adults especially with comorbidities like diabetes or hypertension.

- $\quad$ Pregnancy (virus can be transmitted from mother to fetus)

- Immunocompromised individuals

- Genetic background of the host

- Viral serotype
- Secondary infection by heterologous serotype

- Poor nutritional state

Pathophysiology of Plasma Leakage. The pathophysiological hallmark of DHF/DSS is plasma leakage and deranged hemostasis. Plasma leakage is caused by increased capillary permeability which may manifest as hemoconcentration -- a relative increased in red blood cell count or hematocrit in relation to decrease plasma volume. Plasma leakage is a process where the protein rich fluid component of the blood leaks into the surrounding tissue, primarily in the pleural, peritoneal, and pericardial cavities. The most common method of monitoring leakage, though insensitive due to parenteral fluid therapy, relies on serial HCT measurement, with a rise of more than $20 \%$ from baseline, considered evidence of significant leakage [44]. To determine early capillary leak or assess even small amounts of pleural effusion/ascites, thoraco-abdominal ultrasonography is a recommended tool [50]. Vascular leak is apparent 3 to 6 days after the disease and last about 24 to 48 hours. A sudden and extensive plasma leakage may result in DSS or death. Typically, patients undergo defervescence phase marked by an abrupt drop in body temperature, at which point the illness may either proceed to serious complications or wane to recovery. This means there is a rapid and complete reversal, suggesting that the leak is likely cause by inflammatory mediators, rather than infection of the endothelium [51].

The mechanisms causing vascular permeability during severe dengue are not fully understood, but there is evidence that reactive oxygen species, enzymes, and pro-inflammatory cytokines (i.e., TNF $\alpha$, IFN $\gamma$, IL-6, and IL-8) produced by activated T-cells can break down the endothelial glycocalyx layer. This allows plasma to reach the underlying intercellular junctions and leak out into the tissue [51]. Glycocalyx is an endothelial cell coat that acts as a primary barrier against leakage of proteins and fluid across the vascular wall. Changes to glycocalyx are transient as leakage resolves spontaneously. Although glycocalyx plays a crucial role in fluid fluxes, the balance of hydrostatic and oncotic pressures is consequential in plasma leakage. Others suggest that endothelial cell activation caused by monocytes, T-cells, and the complement system mediate plasma leakage, generating hypovolemia and shock state in severe cases [52]. Moreover, impaired platelet function and endothelial cell damage due to the cross-reactive Abs. anti-NS1, prM, and E viral proteins could increase the risk of vascular fragility, leading to hemorrhage and plasma leakage in DHF/DSS [31, 53].

Another mechanism that causes capillary leakage is thought to be antibody-dependent enhancement (ADE), an immune enhancement cause by heterotypic secondary infection. However, some authors question this theory as capillary leakage is also seen in significant numbers in primary infection [54]. In addition, other factors implicated in this phenomenon include viral virulence, molecular mimicry, and immune complex and/or complement mediated dysregulation, and genetic predisposition, all of which have been shown to correlate with plasma leakage and disease severity [55]. The precise way in which capillary permeability is altered is not clear, but it is more likely to be functional change rather than structural damage, as dengue shock is rapidly recoverable, and no inflammation is evident in the leaking surfaces [6].

Secondary Infection is worse than Primary Infection in Dengue. The pathogenesis of severe dengue is widely associated with secondary infection of a heterologous serotype. Approximately $90 \%$ of severe dengue cases are associated with secondary heterotypic infection, while the remaining 10\% result from primary infection [56]. Many factors such as genetic background, underlying disease state, coinfections, immune response diversity, and viral load may play role in the pathogenesis of severe dengue during a primary infection [57]. Primary infection with any of the 4 DENV serotypes confers life-long immunity to the homologous serotype. However, sequential secondary dengue infections by different serotypes are a risk factor for DHF/DSS, which is 
associated with significant morbidity and occasional death. The death rate of untreated dengue patients was around $20 \%$, but with early diagnosis and proper clinical management, mortality rates of less than $1 \%$ are possible even among DSS cases [22, 27].

Proinflammatory cytokines including IL-8, IL-10, and type 1 IFNs are secreted to initiate inflammation and to control the DENV replication at the early stage of infection. Secondary DENV infections and severe disease in DHF/DSS patients have elevated cytokine levels including IL1, IL-2, IL-6, IL-18, TNF $\alpha$, MCP-1, and most strikingly a very high IL10 level [58-59]. Since the host operates on a critical balance of immune responses, dysregulation of these cytokines may cause dengue pathogenesis. The pathogenesis of dengue in secondary infection is attributed to multiple factors including host factors, vector density, prior immunity, viral load, NS1 viral antigen, anti-NS1 Abs, infecting serotype, DENV genome variation and ADE [56]. The severe dengue manifestations are mainly ascribed to the synergistic effect of all these factors [43, 47]. For comprehensive understanding of the pathogenesis of DENV infection, the readers are referred to reference [47]. Thus, the innate immune response and the inflammatory mechanism and/or adaptive immune response protect us against pathogens. However, they can also be harmful in that overproduction of various normally beneficial mediators and uncontrolled systemic responses can cause illness and even death.

The statement that the severe manifestations of dengue, such as coagulopathy, multi-organ impairment, and shock occur paradoxically late in the disease course when the virus is no longer detectable in blood, and are likely to be driven by an excessive host immune-mediated response $[1,44,60]$. The reasons include 1) severe dengue more often occurs in secondary infection with heterotypic virus when the viral load falls; 2) DENV replication may occur in some organs when viremia is no longer detectable; and 3) the peak in symptoms, vascular leak, and viral control coincide with cytokine storm, which is characterized by high circulating levels of proinflammatory mediators including TNF, IFN, chemokine ligand 5, and vascular endothelial growth factor as well as the anti-inflammatory cytokine IL-10. This cytokine storm has been implicated to trigger increased vascular permeability and multiorgan failure, but resolves relatively quickly upon patient convalescence [22, $32,36]$. In this context, in studying DENV virulence, both the host and viral factors should be considered.

The cross-protection against secondary heterologous serotypes last only for 3 to 4 months, although others have observed 1 to 2 years following primary infection [61,62]. Third or fourth sequential infections are not pathogenic [62]. The longer the interval between primary and secondary infections, the higher the risk of developing DHF/DSS [1]. This is because the viral titers might have fallen to the point where they no longer provide significant cross-protective immunity [47]. The waning cross-reactive heterologous Abs is implicated in the occurrence of severe dengue through "antibody dependent enhancement."

\section{Implication of Antibody-dependent Enhancement in Severe} Dengue. ADE is thought to be the upshot of secondary infection with neutralizing Abs as the key factor in the pathogenesis. ADE occurs when the Abs generated from primary infection cross- react with the secondary heterotypic virus, and instead of neutralizing, they bind/embrace the virus forming virion-antibody immune complexes. These Abs act as a "Trojan horse," allowing these complexes to enter the host's cells via fragment crystallizable $(\mathbf{F c})$ gamma receptor, Fc $\gamma \mathrm{R}$ - bearing cells, like monocytes and macrophages, and exacerbate the immune response [64,65]. This leads to amplification in viral replication. The resultant increase in viral load starts an immunopathogenic cascade, leading to an exaggerated activation of cross-reactive dengue-specific T cells, increased cytokine production and complement activation and ultimately to vascular leak and DHF/DSS [63].
The mechanisms involve in ADE include 2 pathways: phagocytic Fc $\gamma \mathrm{R}$ and complement receptor pathway [64]. After interaction with the virus forming virus-antibody complex, most of these complexes are then bound by $\mathrm{Fc}$ receptors on phagocytic cells, resulting in their internalization and destruction by the phagocytic cells. Some of the complexes, however, are bound by complement components and are either phagocytosed via expressing C3 receptors or lyzed by the complement components. Usually, the process or effect of phagocytosis is virus degradation, however, if the virus is not neutralized, either due to low affinity binding or to the presence of sub-neutralizing concentrations of Abs, the $\mathrm{Ab}$ binding might result in a virus escape leading to enhanced infection or ADE. Thus, phagocytosis, in this case, can cause viral replication with subsequent death of immune cells [64].

Another example of ADE in a setting of severe primary dengue are infants born to DENV-immune mothers. Before 4 months of age, babies are protected by the passively derived maternal IgG Abs against a heterotypic DENV. However, by age 4 to 12 months, due to waning or decay of these Abs, instead of neutralizing the DENV, they link and help them enter the host cells via Fc $\gamma \mathrm{R}$ - bearing cells, resulting in severe dengue disease through ADE. By the age of 1 year old, the complete disappearance of these Abs makes the child open to normal infection [63].

In the context of a heterologous secondary infection, memory B cells produced against the primary infection will respond quickly, generating high titers of Abs that will escalate the current infection rather than neutralizing the virus. This reaction is another effect of immune enhancement in ADE. Moreover, immune complex infection of ADE not only facilitates the virus entry process, but also suppresses innate and adaptive cellular immune responses, increasing intracellular infection and generating inflammatory cytokines and chemokines that together contribute to the development of severe disease [65].

Co-infection of Multiple DENV Serotypes. The presence of multiple DENV serotypes in a single patient is possible when two or more serotypes circulate at the same time in the endemic area. Moreover, coinfection can be further enhanced by the multiple feeding behavior of AMs [66]. Concurrent infections can be verified by RT-PCR assay which offers accuracy in determining the serotype-specific diagnosis of various circulating DENV. Patients may acquire double infection either by a single bite from a female mosquito infected with 2 different DENV serotypes or by simultaneous or alternate bites from 2 or more vector mosquitoes with different serotypes. The former, because it is a single bite, even if it contains/carries 2 different DENV serotypes, the transmitted viral infectious dose or load is the same to that of a monoinfected patient. As a result, the clinical disease severity or viremia, though may vary slightly depending on the serotypes, are not significantly different with the mono-infected patients [67].

However, in the latter, when 2 or more bites occur simultaneously/subsequently in a day by different vector mosquitoes carrying either different or the same viral strains, this will likely Increase the DENV viremia. High viral load early in the course of infection has been linked to severe dengue with increased vascular permeability. Simply put, because of the increased viral load, our immune system must work twice harder to fight off the disease. Otherwise, our body will be overwhelmed by the side effects of viremia with catastrophic result. Hence, it is tempting to speculate that co-infection contributes in some way to severe dengue infection and could be the reason why a certain healthy individual succumbs to primary DENV infection. This is what we called "super-infection" [67]. Likewise, infants are associated with a higher mortality rate than those of older children because of the relatively high viral loads and inherent poor capacity to compensate for vascular leakage and other systemic organ dysfunction. DENV co-infected patients are skewed towards more severe clinical manifestations compared to mono-infected patients [66]. Another fallout of co-infection 
is the possibility of inter-serotype recombination, which may lead to the evolution of new virulent DENV strain [66].

On the contrary, if mosquitoes are disturbed during feeding thereby injecting only a fraction of a viral infectious dose, in this case, our immune system will have a better chance of fighting off the virus, resulting may be in a mild flu like symptoms or just an asymptomatic manifestation.

Co-infection of Dengue and COVID-19. Yes, especially in areas where both viruses are epidemic. Some clinical clues can orient physicians to suspect both diseases. However, this co-infection is a medical concern because it can be difficult to clinically distinguish DENV from COVID-19 based entirely on the initial clinical and laboratory features as both are somewhat similar but require different clinical management [68]. Common symptoms include fever, diarrhea, and respiratory symptoms, such as cough and sore throat, and laboratory findings of thrombocytopenia and leukopenia, and the occurrence of 'cytokine storm' [68]. Aside from these, both infections could cause widespread multiorgan involvement like the lymphoid tissue, liver, heart, kidney, and the skin, suggesting a broad systemic infection. Although both are caused by a virus, their transmission varies: dengue, by infected female AMs bites, and COVID-19 through viral aerosol. Moreover, their pathogenesis, disease course and recovery are different [68]. To confirm the presence of dual infection, a simultaneous laboratory tests showing positive for RT-PCR assay of nasopharyngeal swabs specimens for COVID-19 and an RT-PCR, NSI, IgM, and IgG Abs tests for dengue are suggested.

On this premise, a co-infection of dengue and malaria is feasible considering that both are vector borne diseases with shared endemic profiles and symptoms. Coinfections with any of these diseases could have fatal outcome if left undiagnosed [68a]. This underscores the importance of an accurate and timely diagnosis to prevent the spread of diseases and to design therapeutic interventions.

Cytokine Storm in Dengue. Broadly speaking, cytokine storm is a cascade of exaggerated immune responses in which the immune system produces too many inflammatory cytokines, sometimes leading to organ damage and death. Cytokines (CKs) are soluble low-molecular weight proteins secreted by many cell types that are involved in cell-to-cell communication, and function as mediators of inflammation and immune responses [69]. Simply put, they are cell-signaling messenger molecules that regulate immune cell maturation, growth, and responsiveness. To evoke an immune response, CKs bind to receptors on the membrane of target cells and elicit their effects through the activation of an intracellular signaling cascade that regulate local and, at times, systemic inflammatory responses. Although $\mathrm{CK}$ is not considered a disease by itself, their presence provides invaluable clues of a serious medical issue [69].

Normally, cytokines help coordinate the response of immune system to fight viral infections. which means that when we get sick, our immune system protects us. However, occasionally due to either genetic factors or rampant dengue viral infections, our immune system can go into overdrive/awry. The body suddenly produces too many CKs beyond control. Cytokine storm is a potentially fatal reaction, associated with high death rates during the 1918 flu pandemic and/or the 2003 SARS epidemic [69]. Many scientists have observed that a high viral load and activation of high numbers of nonprotective T cells can result in a "storm" of inflammatory cytokines and other mediators [1], and is thought to contribute to disease pathogenesis and vascular leak [68].

In severe dengue, a deviation of the protective immune response into a dysfunctional program may occur, leading to cytokine release syndrome with severe inflammation and eventually, multisystem failure. Some of the CKs that play a significant role in the development of acute inflammatory responses include IL-1, IL-6, and TNF- $\alpha$. While some groups are pro-inflammatory, others are anti-inflammatory, like type 1 IFN which helps put the brakes on inflammation. This is an important balance, since too much inflammation causes serious complications. Thus, it is not just which cytokines are activated by the host-immune responses - it is also a matter of balance [69].

Laboratory Diagnosis. Presumptive and Confirmatory Laboratory (lab) Tests to Determine Dengue Infection. Because the initial signs and symptoms of DENV infection may be asymptomatic or a nonspecific febrile illness, patient diagnosis and management should be based on clinical manifestations and abnormal lab findings [72]. Lab tests for diagnostic workup and confirmation of dengue include one or more of the following:

- Non-specific tests: Complete blood cell count (CBC), liver function tests, kidney function tests, serum protein and albumin levels, coagulation tests.

- $\quad$ Specific tests: Serology for antibody detection, non-structural protein 1 (NS1) test, or a reverse transcriptase polymerase chain reaction (RT-PCR) for viral genomic sequences.

Complete Blood Cell Count. In most cases, a CBC is recommended for suspected dengue. Dengue fever is characterized by thrombocytopenia (platelet count $<140 \times 10^{9} / \mathrm{L}$ ) and leukopenia (white blood cell count (WBCs) $<4 \times 10^{9} / \mathrm{L}$, rising hematocrit $($ HCT) $>5-10 \%$, but no evidence of plasma leakage [52]. Leukopenia, with lymphopenia, is seen near the end of the febrile phase. Lymphocytosis with atypical lymphocytes (AL) commonly develops before defervescence or shock. It appears that there is an inverse relationship between AL \% and platelets as the higher the AL the lower the platelet count is. The increase in AL \% is associated with severity of dengue infection [70].

In DHF, it is characterized by thrombocytopenia (PLTs $<100 \times 10^{9} / \mathrm{L}$ ) and $\mathrm{HCT}$ rise to $>20 \%$ [63]. Hemoglobin value is also significantly higher especially in patients with plasma leakage.

Although a drop in PLTs below $100 \times 10^{9} / \mathrm{L}$ may also be observed in dengue fever, this is a constant feature of DHF, and it is usually observed on day 3 to 8 of the illness. A rapid decrease in PLTs with a concomitant rise in HCT suggests a likely progression to shock [5]. In this case, the platelet count should be monitored at least every 24 hours to check for the early recognition of DHF. A progressive increase in HCT level begins 3 to 4 days after fever onset. If HCT level increase $>20 \%$ and accompanied by marked platelet depletion, this may precede DHF and shock. HCT then should be monitored every 24 hours to facilitate early recognition of DHF, and every 3 to 4 hours in severe cases of DHF or DSS. Thus, a rapid decrease in platelet count with concurrent increase in HCT value may represent as indicator for progression to severe dengue [71].

Liver Function Tests. Hepatic involvement is common in dengue, and liver enzymes are frequently elevated in all severity grades. The aspartate aminotransferase and alanine aminotransferase are slightly elevated in patients with DHF who have acute hepatitis [72].

Hypoproteinemia or Low Albumin is well recognized during the critical phase, and correlates with severity of leakage and/or hemoconcentration [44].

Kidney Function Tests. The creatinine and blood urea nitrogen (BUN) levels are raised. Elevated BUN levels are observed in those with shock. Acute kidney injury is uncommon [44].

Coagulation Studies: Coagulation studies help clinicians in the care and management of patients with severe hemorrhagic manifestations. Prothrombin time/INR and activated partial thromboplastin time are elevated in the acute phase, however natural anticoagulants such as protein $\mathrm{C}$ and protein $\mathrm{S}$ and antithrombin III are significantly reduced, reflecting capillary leakage alone [73]. Low fibrinogen and elevated fibrin 
degradation product levels are signs of disseminated intravascular coagulation.

Confirmatory Lab Tests for Dengue. Lab diagnosis for confirming DENV may involve detection of the virus, viral nucleic acid, antigens or Abs, or combinations of these methods. In the early stages of the illness, virus isolation, nucleic acid or antigen detection can be used to diagnose the infection. At the end of the acute phase of infection, serology is the method of choice.

NS1 Protein. NS1 can be expressed both as membrane-associated antigen and as a soluble, secreted form in the serum. Their presence in an infected cell can trigger a host immune antibody response. Serum levels of secreted NS1 correlate with viral titers and DENV pathogenesis, and can be detected by the enzyme-linked immunosorbent assay (ELISA) during the first 1-7 days of illness. Since NS1 can be detected early within 24 hours of the infection, and up to 9 days in the patient's sera, [32] many diagnostic assays have been produced, [74] including antigen-capture ELISA, measurement of NS1-specofic IgM, and IgG responses. NS1 antigen test is useful to confirm a clinically suspected infection (symptomatic patient).

Limitations: Test does not differentiate between dengue serotypes but have a higher sensitivity in primary infection (first time infection) than in secondary infection (second time infection with any serotype of DENV) [74a].

Immunoglobulin (Ig) M, IgM - The IgM antibody become detectable 4 to 7 days following infection and it can be detected by the MAC-ELISA assay. IgM levels are detectable by days

3 to 4 of illness in $50 \%$ of hospitalized patients, by day 5 in $80 \%$, and by days 6 to10 in 93 to $99 \%$ of cases [6]. IgM levels peak 2 weeks after the onset of fever and generally decline to undetectable levels over the next 2 to 3 months. Because IgM does not cross the placenta, it is a reliable marker of the infant's primary immune response. The test can help differentiate between primary and secondary infection. High IgM Abs suggest a recent infection.

Limitations: A false negative may result if conducted during secondary infection as IgM levels are significantly low. Likewise, it should not be done early, before day 4 of exposure, as IgM Abs are detectable starting 4 to 5 days after illness. False-positive results due to cross-reactivity with other flaviviruses, for example vaccination against yellow fever virus [74a].

IgG ELISA. IgG is detectable at low titer at the end of the first week, 7 to 10 days of the illness and rise dramatically in 2 weeks. IgG titers decrease by day 49 but can remain in the blood for a lifetime. High titers of IgG Abs are a criterion of secondary infection.

Limitations: This test is not advised for acute infections. Both the IgM and IgG Abs detections are not useful for DENV serotyping [74a].

IgM/IgG ratio. To distinguish primary from secondary DENV infections, the IgM/IgG ratio test is commonly used. Dengue infection is defined as primary if the $\operatorname{IgM} / \operatorname{IgG}$ ratio is greater than 1.2 at $1 / 100$ dilution or $1 / 20$ dilution, and secondary infection if the ratio is less than 1.2.

Limitations: All the above tests can not differentiate between dengue serotypes.

\section{Interpretation of Test Results}

- $\quad$ Patients positive for $\operatorname{IgM}$ test are classified as presumptive recent DENV infections.

- If NS1 test is positive for dengue, a current dengue diagnosis is confirmed.
- If NS1 test is negative but the IgM Ab test is positive, the lab diagnosis is presumptive DENV infection.

- If both IgM and NS1 test results are negative before day 8 of illness, results are considered unconfirmed, and a second sample should be obtained after day 7 of symptoms for additional serologic testing.

- If after day 7 of illness and both the IgM and NS1 test results are still negative, the test is considered as negative for recent infection.

If the IgM test results change from negative to positive in paired samples: first sample tested during the first 7 days of illness and second sample after symptoms subsides, the test is considered as current dengue infections [74a].

Molecular Tests for DENV: Reverse Transcriptasepolymerase Chain Reaction (RT-PCR). It is a primary test to detect the viral genome, the genetic material, in the blood. The test should be done within 5 days after the onset of symptoms and can be used to determine which of the 4 different serotypes of DENV is causing the illness. The test has a $90 \%$ sensitivity and $95 \%$ specificity.

Limitations: The test can be performed only in certain laboratories.

Plaque Reduction Neutralization Test (PRNT). Gold standard to characterize and quantify circulating level of anti-DENV neutralizing antibody.

Limitations: Available only in reference laboratory.

\section{Cautions:}

- Laboratory test results should be used in conjunction with clinical manifestations.

- For valid results, lab tests should follow the timing protocol for certain test. For example, NS1 and PCR assays should be performed within 5 days after the symptoms appear: IgM Abs after 3 days of illness, IgG Abs after 7 days of infection. Other variables for testing accurately include the type and quality of the samples.

- Before testing, obtain patient clinical history of blood transfusion or other blood products within the last several months, infection with other flaviviruses, like Zika virus, West Nile virus.

- The significance of a negative results in an immunosuppressed patient is unclear.

Thrombocytopenia in DENV. Thrombocytopenia (TCP) and platelet dysfunction are common in DENV infection and has been used as a potential indicator of clinical severity and outcome. Several mechanisms have been suggested in DENV-associated thrombocytopenia [31, 75, 76]. Including the suppression of the bone marrow progenitor cells, antibodymediated platelet destruction, platelet destruction due to increased apoptosis, complement-mediated platelet lysis, DIC platelet consumption, and hemophagocytosis. TCP is initially due to marrow suppression during the febrile phase of the illness. Megakaryocytes are the main target for DENV in the bone marrow by suppressing megakaryopoiesis through inhibition of proliferation and differentiation of hematopoietic progenitors and alteration of cytokine production in bone marrow. Viral infection of megakaryocytes can increase their apoptosis and decrease maturation and ploidy. Moreover, there is an increased peripheral destruction of platelets.

Platelet count (Plts) in dengue infection showed a significant decrease on day 4 of the illness. 
Plts $<100 \times 10^{9} / \mathrm{L}$ are observed both in DF and DHF but are more common and severe in DHF. Previous studies showed that DHF in adults without shock, even with moderately decreased platelets on day 3 to 7 may reached normal levels on the day 8 or 9 [77]. In adults, a Plts of

$10 \times 10^{9} / \mathrm{L}$ and a HCT of $>50 \%$ are significantly associated with bleeding manifestations. However, different studies showed contrasting bleeding results on patients with platelets below $20 \times 10^{9} / \mathrm{L}$. One study showed no correlation between bleeding and platelet count [78] while others showed bleeding to occur more often [79].

Prophylactic platelet (PIt) transfusion refers to Plt transfusion without clinical bleeding, in contrast to therapeutic Plt transfusion, with clinical bleeding [79]. Most clinical guidelines recommend Plt transfusion be given to patients with serious hemorrhagic manifestations, or have a very low Plts falling below $10-20 \times 10^{9} / \mathrm{L}$ without hemorrhage or $50 \times 10^{9} / \mathrm{L}$ with bleeding or hemorrhage [26]. Based on Plts and bleeding risk, dengue patients can be categorized into high, moderate, slight, and no risk groups with Plts of $<20 \times 10^{9} / \mathrm{L}, 21-50 \times-, 50-100 \times-$, and $>100 \times 10^{9} / \mathrm{L}$, respectively at the time of admission [80]. In this context, patients belonging to the high-risk group are at high risk of bleeding and thus should be given a prophylactic Plt transfusion [81].

However, the efficacy of Plt transfusion is questionable. In a study of pediatric patients with DSS, preventive transfusions of platelets and fresh frozen plasma did not reduce bleeding or expedite Plt recovery, rather, it caused higher frequency of pulmonary edema and prolonged hospitalization [82]. Similarly in adult dengue patients, Plt transfusion did not prevent the development of severe bleeding, nor shortened bleeding cessation or increased platelets, and was associated with significant side effects [79]. Although there is a need for therapeutic Plt transfusion, it should not be routinely performed in the management of dengue - only in cases where significant bleeding is evident.

Hemorrhagic Manifestations in Dengue. Around the time of defervescence, mild hemorrhagic manifestations such as petechiae, epistaxis, purpura, and gingival bleeding are comparatively common even in non-severe cases. The mechanisms associated with the bleeding in DHF are not completely known but may include thrombopathy, vasculopathy and DIC. Thrombopathy consists of TCP and Plt dysfunction. DIC is noticeable in patients with shock and, with prolonged shock, may cause further bleeding and a fatal outcome. Major bleeding may be due to severe thrombocytopenia, platelet dysfunction and profound coagulopathy [83].

Coagulopathy in Dengue. Coagulopathy is common in dengue patients. Increased vascular permeability is one of the main effects of DHF and is the cause of shock [83]. The etiology of coagulopathy is poorly understood, but the condition is probably cause by the loss of essential coagulation proteins because of plasma leakage. Interaction between dengue NS1 protein and the endothelial glycocalyx layer may cause a change in filtration characteristics leading to plasma protein leakage. Hypoalbuminemia and proteinuria occur as a result of capillary leakage and correlates with severity. Because all the coagulation proteins have molecular weights closer to albumin, when plasma leaks, many of these proteins are likely to leak as well. With respect to the natural anticoagulant proteins $\mathrm{C}, \mathrm{S}$, and antithrombin 1ll, which are predominantly synthesized in the liver, the low circulating levels are likely related to leakage and correlate with the severity of the disease. In most cases, there will be an elevated PT/INR, APTT, and decreased fibrinogen. Because fibrinogen is an acute-phase protein, a considerable amount is typically consumed before plasma levels decrease. If the consumption of fibrinogen in DSS involved classical DIC, a prolonged PT and PTT and D-dimer might be expected. Clinically significant bleeding was unusual. Coagulopathy is typically worsened in the critical phase and among those with more severe plasma leakage [83].
Treatment for Dengue Infection. There is no specific treatment for dengue fever. The treatment remains supportive and symptomatic, with particular emphasis on careful clinical and fluid management as well as balance nursing care. Get plenty of bed rest and drink fluids for adequate hydration. Aspirin, ibuprofen, and non-steroidal antiinflammatory drugs should be avoided as they can worsen bleeding problems worse. Tylenol/acetaminophen or paracetamol can be used to relieve fever and pain. If the condition progresses to DHF/DHS, prompt fluid resuscitation to restore plasma volume should be implemented urgently, followed by ongoing fluid therapy to support the circulation at a level just sufficient to maintain critical organ perfusion. Isotonic crystalloid solutions should be used, and isotonic colloid solutions should be reserved for patients presenting with profound shock or those who do not have a response to initial crystalloid therapy [22].

Blood transfusion can be lifesaving, but it should be used with caution because of the risk of fluid overload. Platelet concentrates, fresh frozen plasma, and cryoprecipitate may also be needed depending on the coagulation profile. Most clinical guidelines recommend that platelet transfusions be given to patients who develop serious hemorrhagic manifestations or have incredibly low platelet counts below $10-20 \times 10^{9} / \mathrm{L}$ without hemorrhage or $50 \times 10^{9} / \mathrm{L}$ with bleeding or hemorrhage [31].

Despite the huge burden of morbidity, there are no antiviral agents licensed to treat dengue. Dengue-associated hyperinflammation is an increasingly recognized, but still an under-diagnose phenomenon among patients with severe dengue: mortality is higher in those with hyperinflammation $(39 \%)$ than in those without (22\%) [84]. Some immunomodulatory agents have been proposed for treatment of hyperinflammation in dengue, including an anti-inflammatory agent that blocks specific cytokine IL-1 receptor (Kineret) and the activity of IL-6 (Actemra), [69] and a Janus kinase and Numb-associated kinase inhibitor (Baricitinib) [84]. Kineret targets the IL-1 $\beta$ hyperinflammatory loop, which mediates hyperferritinemia, coagulopathy and fever. Baricitinib targets cellular viral entry and replication, and modulates the proinflammatory cytokine response to viral infection. Incorporating inflammatory markers into the clinical decision making could support a judicious anti-inflammatory treatment use.

Prognosis of Dengue Illness. The prognosis for dengue is good because of the combined robust innate and inflammatory as well as adaptive immune responses in regulating dengue infection and possibly influencing the disease. The innate immune system response relies on the use of physical barriers like our skin and mucous membrane. Coupled this with our first defender responders, like neutrophils and macrophages for phagocytosis, soluble immunological mediators like interferons that inhibit viral translation and replication, and attack cells, like natural killer cells that can nonspecifically recognize and kill virus-infected or stressed cells. If the first defense is effective, the DENV case may appear asymptomatic. However, when the innate immune system is not enough, the second line of defense of the adaptive immune system is activated to counter infection with specific tailor-made attack responses. This attack can occur in the form of $\mathrm{B}$ and $\mathrm{T}$ lymphocytes, which produce Abs and effector cells that specifically recognize and neutralize the virus [69]..

Long-term Side Effects of Dengue. For the majority of infected cases, patients recover completely, although they are likely to feel ill during the first one or two weeks of the acute illness, and possibly feel ill for about a month. Long-term side effects of dengue infections are rare, especially in asymptomatic patients with strong immunity. However, some individuals suffer side effects after dengue infection including muscle and joint pain, palpitation, depression, anxiety, general malaise, irritability, dizziness, headache, alopecia, rash, and anorexia [85]. To alleviate the side effects: increase fluid intake, have well-balanced diet, and be physically active. 
Aedes Aegypti Mosquitoes. Characteristics of Aedes Aegypti Mosquitoes that Transmit Dengue. The word "mosquito" is Spanish for "little fly". Aedes aegypti mosquitoes (AMs) are small dark mosquitoes, visually distinctive due to their noticeable black and white lyre shape markings on their body and legs (Image 1; Figure 3). AMs are a day-time feeder. Although they most commonly bite during their peak biting periods, 2 to 3 hours after sunrise and several hours before sunset, they may bite and spread infection all year long and at any time of the day [86]. AMs have no teeth, but they have 2 long pointed serrated tubes called proboscis which are very sharp and thin that when they bites may not be felt by the blood host. Only females have the proboscis, for biting. AMs use them to suck blood through capillary action in one tube and pump out saliva which contains protein (anticoagulants) and the DENV in another tube [87].

Both male and female feed on fruit and plant nectar for energy, however, only females bite humans because they need blood for egg development. AMs prefer to live/rest indoors in dark areas, including closets, behind curtains, house walls, under beds, tables, furniture, or underneath homes. Once they are inside the house, they will not leave until you get rid of their breeding sites. While other mosquito species prefer livestock, reptile, or birds, female AMs primarily bite humans and are prone to living inside human habitation, making them dangerous to people. They inflict an innocuous bite on the back of the neck, ankles, or elbows, and are easily distracted during blood meal, causing them to shift and finish their blood meal on another host. Thus, they can feed several times on multiple hosts during one feeding and egg producing cycle, which has implications for disease transmission [87].

Life Cycle of Dengue Mosquito. The entire life cycle for an egg to develop into an adult mosquito takes approximately 8 to 10 days [88]. They have 4 life stages: eggs, larva, pupa, and adult (Figure 3). During the first three stages, AMs usually live-in water. At larva stage, they frequently surface to breath. At the end of pupal stage and metamorphosis to adult stage, AMs crawl to a dry place and off they fly to become a flying syringe [88].

Eggs. The more blood female AMs consume, the more eggs they can lay from 50 to 500 eggs during their lifetime. It takes 2 to 3 days following blood meal for the eggs to fully develop, after which AMs rest for a couple of days before laying eggs. They lay eggs on the surface of stagnant water, or on the inner walls or near the edges of containers, just above the water line. Table 1 lists the containers and mosquito breeding sites. They do not breed in rivers, swamps, creeks, bush land or mangroves. It takes only a small amount or as little as an inch of standing water to attract them to lay eggs. The egg production sites are usually found within or near households, the former are the most perilous sites as they breed in the house. AM eggs are very hardy; they stick to container walls like glue and can lie dormant or survive drying out

(desiccation) for 9 months or a year. Eggs are ready to hatch from a few days to several months. In warm climate, eggs may develop in as little as two days, whereas, in cooler temperature, up to a week to hatch. AMs eggs, however, may not survive when exposed to frost or at temperature below $10^{\circ} \mathrm{C}$ [89].

Larvae. When the water level rises to inundate the AM eggs by rainwater or human cause, it will trigger the larvae to emerge. Their preference for artificial water containers and feeding and resting indoors ensures larval development unhampered even in the absence of rainfall.

Thus, AM larvae may be less susceptible to the effects of climate factors [87]. Larvae live and feed on microorganisms in still water. They are actively mobile and are often called "wigglers." Males develop faster than females, so they pupate earlier. After molting three times, the larva develops into a pupa in as few as 5 to 7 days.

Pupae. Pupae are also aquatic but develop into adult AMs 2 to 3 days after reaching this stage.

Dengue mosquitoes and the Hot Weather. Many different factors can contribute to dengue outbreaks and transmission, including human and vector populations density, and hot temperatures. Temperature plays a vital role in adult vector survival, viral replication, infectivity, and/or migration into previously non-endemic geographic areas. DENV grows and spreads in mosquitoes at a faster rate in higher temperatures than at lower or fluctuating temperatures, suggesting that weather conditions could influence DENV outbreaks. When the environmental temperature is $28^{\circ} \mathrm{C}$ or higher, there is rapid viral growth and much earlier spread of DENV in the AM salivary glands, signifying more infectious AMs. While high temperatures and intense humidity may force humans indoors, the same conditions energized mosquitoes, allowing them to fly further and bite more often. On the other hand, at cooler temperature below $18^{\circ} \mathrm{C}$, DENV grows at slower rate, and may not even spread to salivary glands, implying that cooler temperatures can render DENV spread by AMs ineffective. This may explain why dengue is rare in cooler countries, where AMs may also exist [93].

DENV Spread by Asymptomatic Individuals to Mosquitoes. Although they show no signs or symptoms of the disease, they are a carrier and can infect female AMs who bite them.

Such risk makes it important that everyone takes precaution, stay alert, and to avoid being bitten and infected in the first place.

\begin{tabular}{|l|l|l|}
\hline \multicolumn{1}{|c|}{ Indoor } & \multicolumn{1}{|c|}{ Outdoor } & \multicolumn{1}{c|}{ Outdoor } \\
\hline Buckets & & \\
Tin cans & Tree holes & Manholes \\
Air-con vents & Flowerpot plates/vases & Ornamental fountains \\
Water coolers & Discarded tires & Dishes under potted plants \\
Cups & Plates under potted plants & Closed perimeter drains \\
Bowls & Cemetery vases & Gully traps \\
Toys & Clogged rain gutters & Flowerpot trees \\
Plastic containers & Trash containers & Fountains \\
Septic tanks & Discarded bottles and tins & Bird baths \\
Toilet bowls & Pots/Potholes & Pet watering dishes \\
Wet shower floors & Boats & Rain barrels \\
Toilet tanks & Leaf Axils of various plants & Clogged drains \\
Ant traps & Water bowls for pets & Wading pools \\
Flower vases and saucers & Drums & Bottles/Bottle cups \\
Domestic drinking water pot & Shell, husks, pods from trees & Plastic covers \\
\hline
\end{tabular}


Mosquitoes Travel/Fly Range. AMs tend to live and hang around nearby their breeding locations, especially when food is abundant, and travel only as far as 50 to 200 meters away from this local environment [94]. However, if there is scarcity of food (blood and nectar) or if new breeding sites are required, they may travel further distances. In general, a biting mosquito prefers to fly at a height below 25 feet, because that is where the food is. AMs are sneaky and prefer to fly low, below the heights of human kneecaps, to bite hosts on their ankles and calves. However, they are known to fly 50 or more feet above ground. To reach indoor environments, AMs could easily fly through the windows into the second, third, or fourth floor of a human occupied building [95].

DENV Transmission from Mosquito to her Offspring, to Other Mosquitoes, or Pets and Domestic Animals. Humans cannot infect each other, but they can infect female mosquitoes, which pass the virus both to her eggs (female offspring) and to human bite victims. However, they are unable to spread it to other adult mosquitoes [96]. Monkeys are the known animals to be affected; other animals like dogs do not carry or spread dengue.

Some People are More Attractive to Mosquitoes Than Others. Essentially, female mosquitoes need human blood for their egg development, so we are a source of nourishment. They are attracted by several elements including heat, light, smell, body odors and movement, and some chemical compounds emitted by humans. AMs have several sensors for tracking their prey, including:

- Chemical sensors - AMs can sense the emitted carbon dioxide $\left(\mathrm{CO}_{2}\right)$, ammonia, lactic acid, and octenol, along with chemicals from the skin, like sweat, as far as 150 feet away. Scented lotions and perfumes are also known to attract them. Pregnant women and obese people attract more mosquitoes than ordinary individuals because they exhale more $\mathrm{CO}_{2}$, in addition to having a high metabolic rate that may raise body temperature that attract AMs at a higher rate.

- Heat sensors - mosquitoes can detect body heat and locate the capillaries for tapping. Alcohol consumption not only leads to more chemical secretion through skin that attracts AMs but can also increase body temperature. The higher the temperature, the easier for AMs to track a host. Dark clothing can also attract AMs because they retain more heat than light colored clothes.

- Visual sensors - they use their vision to locate targets from a distance, thus, if you are moving and wearing dark clothing that contrasts with the light background, signals to an AMs that the object is "alive" and full of blood.

Mosquitoes and Smoke. All insects have mortal fear of smoke because it is a harbinger of flames and flames means instant death. AMs require oxygen for respiration, and since smoke prevents this process, they are repelled by it. Although mosquitoes are attracted to the released $\mathrm{CO}_{2}$ from their human prey, they are nonetheless repelled by other noxious chemicals, carbon monoxide, nitrogen oxides, and several other compounds that can inhibit or kill them. Smoke also suppresses their chemical receptors for tracking blood hosts. Nonetheless, smoke as a mosquito repellent has only minimal applications to stop the spread of DENV as smoke causes air pollution and an environmental hazard and its effect is only temporary.

HIV or CovID-19 Transmitted Through Mosquito Bites. Mosquitoes lack receptors or host cells in which the HIV or COVID-19 can replicate. Instead, HIV or COVID-19 is digested inside mosquitoes' stomach and broken down without being passed on. Mosquitoes or no mosquitoes, it is important to keep following a healthy protocol to protect ourselves and others.

Prevention and Control of DENV. The only way to truly prevent dengue virus infection is to avoid being bitten by a vector mosquito. Vector prevention and control through

public awareness campaigns, biologic and chemical targeting of mosquitoes and removal of their breeding sites remain the mainstay of dengue prevention. Although this approach seems effective, it has failed to stop the disease in endemic countries.

There are several ways to prevent or reduce the transmission of DENV/mosquito bites:

- Foremost is to eliminate mosquito habitats. At least once a week, empty and clean or cover breeding sites or containers that hold standing water. See Table 1 for the list of containers and habitats. In case of wells or pools of stagnant water - spray it with oil or soap. Soap reduces the water surface tension thereby depriving larvae of needed air to survive.

- Add mosquito-eating fish, such as guppies, to water storage containers or fishponds.

- Stay in well-screened door and window. Structural barriers like screens or nettings can keep mosquitoes out.

- Wear light colored protective clothing. Wear long pants, longsleeved shirts, socks, and shoes.

- Use mosquito repellent. Apply $10 \%$ Diethyl Toluamide (DEET) in your skin especially if you know you will be exposed to insects. Consult physician what to use for children.

- $\quad$ Avoid scents. Heavily scented perfumes or soaps may attract mosquitoes.

- $\quad$ Add bug-repellent plants to your yard. They absolutely hate lavender, lemongrass, geraniums, citronella, basil, mint, lemon balm, rosemary, garlic, catnip.

Everyone can help control mosquitoes. Preventing mosquito-borne disease requires massive efforts on the part of individuals, communities, and government. If needed, a community clean up event can be helpful. Conduct public education campaigns focusing on reducing or eliminating larvae habitats. Established a well-designed surveillance system. So that when an outbreak occurs, health authorities act quickly to identify the source of the incidence and attempt to prevent new clusters of illness. Because of the endemicity and/or continuous dengue infection, a friendly weekly or monthly radio or TV ads reminder/education will certainly be useful.

Quarantine People with DENV. Dengue cases do not require quarantine because it is not spread from person to person, unlike COVID19 which is spread via aerosol. Quarantines are extreme measures used to avoid the spread of diseases by direct human-to-human contact.

Impact of COVID-19 Lockdowns on Dengue Transmission. Mandating people to lockdown at home has helped stop the spread of the COVID-19 virus pandemic, but may spur a potential change in the rate of dengue transmission. Disruption to routine vector control programs, such as indoor residual spraying or space spraying that kill adult mosquitoes, will negatively impact the effectiveness of these programs. Interruption 
to cleaning breeding habitats will also likely lead to an increase in mosquito populations. Lockdowns compel more people to stay at home, providing more interaction between humans and mosquitoes.

On the other hand, restricting infected human movements and decreasing travel volume and distance will negatively impact on dengue transmission. Lockdowns could slow or even prevent the spread of a dengue transmission, from the high transmission intensity urban centers to the suburbs and remote provinces. Likewise, restricting international movement may reduce the risk of importation of novel dengue virus [96a].

Vaccine in Dengue. Only one vaccine for DENV is currently approved in different countries, including Philippines, Mexico, Thailand, Indonesia, and Singapore [97,98]. Developing a safe and effective vaccine against the dengue disease is challenging because the vaccine must be functionally tetravalent, eliciting simultaneous protection against all 4 DENV serotypes. Vaccination against only one serotype could possibly result in severe dengue infection when infected with another serotype due to ADE. The observation that DHF/DSS is associated with DENV secondary infection poses a special challenge in the development of dengue vaccine, leading to a requirement that such vaccines should induce a robust immune response against all 4 DENV serotypes in the non-immune or naïve as well as previously immune individuals.

In the early February 2016, the world's first dengue vaccine Dengvaxia (CYD-TDV) developed by Sanopi Pasteur, was launched in the Philippines [99]. More than 733,000 children, aged 9 and older were vaccinated with the anti-dengue vaccine. Since some vaccinated children experienced severe dengue disease and even death, by the first week of December 2017, the dengue vaccination program was suspended.

Dengvaxia is a live attenuated tetravalent dengue vaccine used to prevent dengue fever in humans. The vaccine is recommended for use in individuals 9 to 45 years of age who live in endemic regions, with confirmed previous dengue infection. For children with previous dengue exposure, the vaccine is safe and efficacious. Those not previously infected by any DENV serotype are at higher risk for severe dengue infection when vaccinated and subsequently infected with DENV. In this case, the vaccine acts as the first exposure, meaning the body is sensitized to develop Abs and memory cells (high antibody levels protect, low levels enhance). When they are exposed to DENV later, with sub neutralizing Abs, they are at a higher risk of developing severe dengue infection via $\mathrm{ADE}$ (see $\mathrm{ADE}$ for explanation) or the vaccine associated disease enhancement [100]. Put simply, Dengvaxia vaccine could mimic a primary infection when injected in seronegative patients, causing their first true natural exposure or primary infection to result in severe secondary infection. This severe dengue complication is called by Dr. Halstead as "plasma leakage syndrome" [101]. Thus, healthcare professionals must evaluate individuals for prior dengue exposure to avoid vaccination of zero-negative individuals. It is also important to avoid the negative impact on the well-established immunization program for children, as this creates fear and anxiety to parents and the public against the vaccine. Compounded by vaccine skepticisms due to religious beliefs and various conspiracy theories that vaccines contain birth control; some may believe vaccination can cause autism in children.

\section{Conclusion}

Researchers have been actively studying the virus to try to develop drugs to cure infection and vaccines to block infection before it starts. A dengue vaccine has proven difficult to develop, partly because of the 4 subtypes of DENV, each with slightly different viral proteins. This means that an effective vaccine will have to stimulate protective Abs. against all 4 subtypes simultaneously, a feat that has been difficult to achieve.

Despite the advances in technology and science, mosquitoes may pose a risk to health virtually anywhere in the world. They are now global citizens, so we would not be surprised to see them appear almost any place, any time, and anywhere. In fact, our troubles with them are getting worse, making more people sick and claiming more lives, more than thousands to millions of lives, every year.

If the dengue virus would disappear from a local population, even if the mosquitoes returned, they would be merely as a nuisance, not a potential flying syringe vampire.

In the end, humans provide the mosquitoes with all their needs - artificial water containers, shelters, and more food - blood.

\section{References}

1. Martina BEE, Koraka P, Osterhaus ADME. (2009) Dengue virus pathogenesis: an integrated view. Clin Microbiol Rev. 22:564581.

2. Rodenhuis-Zybert IA, Wilschut J, Smit JM. (2010) Dengue virus life cycle: viral and host Factors modulating infectivity. Cellular and Molecular life Science. 67:2773-2786.

3. Carlos CC, Oishi K, Cinco MTDD, Mapua CA, Inoue S, Cruz DJM, Pancho MAM, Tanig CZ, Matias RR, Morita K, Natividad FF, Igarashi A, and Nagatake T. (2005) Comparison of clinical features and hematologic abnormalities between dengue fever and dengue hemorrhagic fever among children in the Philippines. Am J Trop Med Hyg. 73:435-440.

4. Guzman MG, Kouri G. (2002) Dengue: an update. Lancet Infect Dis. 2:33-42.

5. WHO. (2009) Dengue: Guidelines for diagnosis, treatment, prevention, and control. WHO,Geneva, Switzerland.

6. Guzman MG, Halstead SB, Artsob H, Buchy P, Farrar J, Gubler DJ, Hunsperger E, Kroeger A, Margolis HS, Martinez E, Nathan MB, Pelegrino JL, Simmons CP, Yoksan S, Peeling RW. (2009) Dengue: a continuing global threat. Nat Rev Microbiol. 8(Suppl):7-16.

7. PLOS. (2019) Dengue research in the Philippines evolving over time. ScienceDaily.

8. WHO. (2018) Dengue and severe dengue. Fact Sheet N 117 (cited).

9. Quintos FN, Lim L, Julians A, Lacson P. (1954) Hemorrhagic fever observed among children in the Philippines. Philippine J Ped. 3(1).

10. Lim LE, Stransky E. (1956) On infectious acute thrombocytopenic purpura (hemorrhagic fever) observed in Children in the Philippines. Annales Paediatrici Int Rev Pediatrics. 187:309-320.

11. Endy TP, Weaver SC, Hanley KA. (2016) Dengue virus: past, present, and future. Caister.com/dengue.

12. Halstead SB, Yamarat C, Scanlon JE. (1963) The Thai hemorrhagic fever epidemic of 1962 (A preliminary report). J Med Assoc Thai. 46:449-462.

13. Hammon VM, Rudnik A, Sather GE. (1960) Viruses associated with epidemic hemorrhagic fevers of the Philippines and Thailand. Science. 131:1102-1103.

14. Venzon EI, Rudnik A, Marchette NJ, Fabie AE, Dukellis E. (1972) The greater Manila dengue hemorrhagic fever epidemic of 1966. J Phil Med Assoc. 48:297-313.

15. Dizon JJ. (1978) The occurrence of dengue hemorrhagic fever in the Philippines. Asian J Infect Dis. 2:15-17.

16. Yeung J, Faidell D. (2016) Philippines declares a national dengue epidemic after 622 deaths.

17. Hayes CG, Corazon RM, Gonzales A, Ranoa CP. (1988) Dengue infections in the Philippines: clinical and virological findings in 517 hospitalized patients. Am J Trop Med Hyg.39:110-116.

18. Songco RS, Hayes CG, Leus CD, Manaloto COR. (1987) Dengue fever/dengue hemorrhagic fever in Filipino children: clinical 
experience during the 1983-1984 epidemic. Southeast Asian J Trop Med Public Health. 18:284-290.

19. Dash A, Bhatia R, Sunyoto T, Mourya D. (2013) Emerging and re-emerging arboviral diseases in Southeast Asia. J Vector Borne Dis. 50:77-84.

20. Gubler DJ. (2006) Dengue/dengue haemorrhagic fever: history and current status. Novartis Found. Symp. 277:3-16.

21. Leder K, Torresi J, Libman MD, Cramer JP, Castelli F, Schlagenhauf P, Wilder-Smith A, Wilson ME, Keystone JS, Schwartz E, Barnett ED, von Sonnenburg F, Brownstein JS, Cheng AC, Sotir MJ, Esposito DH, Freedman DO. (2013) Geo Sectional surveillance of illness in returned travelers, 2007-2011. Ann Intern Med. 158:456-468.

22. Simmons CP, Farrar JJ, Chau NVV, Wills BW. (2012) Dengue. N Engl J Med. 366:1423-1432.

23. Gubler DJ, Clark GG. 1995) Dengue/dengue hemorrhagic fever: the emergence of a global health problem. Emerg Infect Dis. 1:5557.

24. Reiter P. (1998) Aedes albopictus and the world trade in used tires, 1988-1995: the shape of things to come. J Am Mosq Control Assoc. 14:83-94.

25. Dengue: Guidelines for treatment, prevention, and control. Geneva: (2009) World Health Organization.

26. Daisy Magalit Rodriguez. (2016) The Balance Concept in Nursing New Perspective in Survival and Health. Revised Philippine Edition. Diliman, Quezon City; The University of the Philippines Press.

27. WHO report on global surveillance of epidemic prone infectious diseases. (2005) World Health Organization, Geneva.

28. Kuhn RJ, Zhang W, Rossman MG, Pletnev SV, Corver J, Lenches E, Jones CT, Mukhopadhyay S, Chipman PR, Strauss EG, Baker TS, Strauss JH. (2002) Structure of dengue virus implications for flavivirus organization, maturation, and fusion. Cell. 108 (5):717725.

29. Perera R. Kuhn RJ. (2008) Structural proteonomics of dengue virus. Curr Opin Microbiol. 11:369-377.

30. Li L, Lok SM, Yu IM, Zhang Y, Kuhn RJ, Chen J, Rossman MG. (2008) The flavivirus precursor membrane-envelope protein complex: structure and maturation. Science. 319:1830-1834.

31. de Azeredo EL, Monteiro RQ, de-Oliveira Pinto LM. (2015) Thrombocytopenia in dengue: Interrelationship between virus and the imbalance between coagulation and fibrinolysis and inflammatory mediators. Mediators of Inflammation. Volume 2015. Article ID 313842.

32. Libraty DH, Young PR, Pickering D, Endy TP, Kalayanarooj S, Green S, Vaughn DW, Nisalak A, Ennis FA, Rothman Al. (2002) High circulating levels of the dengue virus nonstructural protein NS1 early in dengue illness correlate with the development of dengue hemorrhagic fever. J Infect Dis. 186:1165-1168.

33. Dengue Viruses / Learn Science at Scitable. (Internet) 2019.

34. (2021) Overview of dengue virus.

35. Espada-Murao LA, Morita K. (2011) Dengue and soluble mediators of the innate immune system. Trop Med Health. 39:5362.

36. Dejnirattisai W, Duangchindra T. Lin CL, Vasanawathana S, Jones M, Jacobs M, Malasit P, Xu X, Screaton G, Mongkolsipaya J. (2008) A complex interplay among virus, dendritic cells, T. Cells, and cytokines in dengue virus infections. J Immunol. 181:5865-5874.

37. (2019) How is dengue transmitted?

38. Schubert F. (2017) How to diagnose dengue fever with lab test.

39. Alvarez M, Rodriguez-Roche R, Bernardo L, Vasquez S, Morier L, Gonzalez D, Castro O, Kouri G, Halstead SB, Guzman MG. (2006) Dengue hemorrhagic fever caused by sequential dengue 1-
3 virus infections over a long time interval: Havana epidemic, 2001-2002. Am J Trop Med Hyg. 75:1113-1117.

40. Muller DA, Depelsenare ACI, Young PR. (2017) Clinical and laboratory diagnosis of dengue virus infection. J Inf Dis. 215:S89S95.

41. Malavige GN, Fernando S, Fernando DJ, Seneviratne SL. (2004) Dengue virus infections /Postgraduate Medical Journal.

42. (2019) Clinical Presentation/Dengue/Centers for Disease Control and Prevention.

43. Lam Vuong N, Thi Le Duyen H, Khanh Lam P, Thi Hoai Tam D, Van Vinh Chau N, Van Kinh N,Chanpheaktra N, Chai See Lum L, Pleites E, Jones NK, Simmons CP, Rosenberger K, Jaenisch T, Halleux C, Olliaro PL, Wills B, Yacoub S. (2020) C-reactive protein as a potential biomarker for disease progression in dengue: a multi-country observational study. BMC Med. 18:35-48.

44. Yacoub S, Wills B. (2014) Predicting outcome from dengue. BMC Med. 147-189.

45. Nascimento EJ, Silva AM, Cordeiro MT, Brito CA, Gil LH, Braga-Nato U, Marquez ET. (2009) Alternative complement pathway deregulation is correlated with dengue severity. PLoS One. 4(8):e67782.

46. Juffrie M, Meer GM, Hack CE, Haasnoot K, Sutaryo, Veerman AJP, Thijs LG. (2001) Inflammatory mediators in dengue virus infection in children: inteleukin-6 and its relation to C--reactive protein and secretory phospholipase A2. Am J Trop Med Hyg. 65:70-75.

47. Bhatt P, Sabeena SP, Varma M, Arunkumar G. (2021) Current understanding of thepathogenesis of dengue virus infection. Current Microbiol. 78:17-32.

48. Wei-Kung Wang, Day-Yu Chao, Chuan-Liang Kao, Han-Chung $\mathrm{Wu}$, Yung-Ching Liu, Chien- Ming Li, Shih-Chung Lin, Shih-ting Ho, Jyh-Hsiung Huang, Chwan-Chuen King. (2003) High levels of plasma dengue viral load during defervescence in patients with dengue hemorrhagic fever: implications for pathogenesis. Virology. 305:330-338.

49. Libraty DH, Young PR, Pickering D, Endy TP, Kalayanrooj S, Green S, Vaughn DW, Nisalak A,Ennis FA. Rothman AL. (2002) High circulating levels of the dengue virus nonstructural protein NS1 early in dengue illness correlate with the development of dengue hemorrhagic fever. J Infect Dis. 186:1165-1168.

50. Venkata Sai PM, Dev B, (2005) Krishnan R. Role of ultrasound in dengue fever. Bri J Radiol78:416-418.

51. Pathophysiology - plasma leakage. Center for Disease Control and Prevention. Dengue Clinical Management, National Center for Emerging and Zoonotic Infectious Diseases.

52. WHO. (2011) Comprehensive guidelines for prevention and control of dengue and dengue hemorrhagic fever. Geneva.

53. Avirutnan P, Punyadee N, Noisakran S, et al. (2006) Vascular leakage in severe dengue virus infections: a potential role for the nonstructural viral protein NS1 and complement. J Inf Dis. 193:1078-1088.

54. Agarwal A, Agarwal M, Gupta V. (2017) Changing epidemiology of dengue fever: newer insights and current concepts. Int J Trop Dis and Health. 26:1-12.

55. Sellahewa JH, Bologna R. (2013) Pathogenesis of dengue haemorrhagic fever and its impact on case management. International Scholarly Research Notices. Article ID 571646.

56. Guabiraba R, Ryffel B. (2014) Dengue virus infection: current concepts in immunemechanisms and lessons from murine models. Immunology. 141:143-156.

57. Kliks SC, Nisalak A, Brandt WE, Wahl L, Burke DS. (1989) Antibody-dependentenhancement of dengue virus growth in human monocytes as a risk factor for dengue hemorrhagic fever. Am J Trop Med Hyg. 40:444-451. 
58. Chakravarti A, Kumaria R. (2006) Circulating levels of tumor necrosis factor alpha \& interferon-gamma in patients with dengue $\&$ dengue haemorrhagic fever during an outbreak. Indian J Med Res. 123:25-30.

59. Yang KD, Wang CL, Shaio MF. (1995) Production of cytokines and platelet activating factorin secondary dengue infections, J Infect Dis. 172:604-605.

60. Screaton G, Mongkolsapaya J, Yacoub S, Roberts C. (2015) New insights into the immunopathology and control of dengue virus infection. 15:745-759.

61. Anderson KB, Gibbons RV, Cummings DAT, Nisalak A, Greene S, Library DH, Jarman RG, Srikiatkhachorn A, Mammen MP, Darunee B, Yoon I-K, Emndy TP. (2014) A shorter time interval between first and second dengue infections is associated with protection from clinical illness in a school-based cohort in Thailand. J Infect Dis. 209:360-368.

62. Halstead SB, Katzelnick L. (2020) COVID-19 vaccines: should we fear ADE? J Infect Dis. 222:1946-1950.

63. Back AT, (2013) Lundkvist A. Dengue viruses - an overview. Infect Ecol Epidemiol.

64. Tirado SM, Yoon KJ. (2003) Antibody-dependent enhancement of virus infection and disease. Viral Immunology. 16:69-86.

65. Guzman MG, Vasquez S. (2019) The complexity of antibodydependent enhancement of dengue virus infection. Viruses. 2:2649-2662.

66. Dhanoa A, Hassan SS, Ngim CF, Lau CF, Chan TS, Adnan NAA, Eng WWH, Gan HM, Rajasejkaram G. (2016) Impact of dengue virus (DENV) co-infection on clinical manifestations, disease severity and laboratory parameters. BMC Infect Dis. 406:17311738.

67. Senaratne UTN, Murugananthan K, Sirisena PDNN, Carr JM, Noordeen F. (2020) Dengue virus co-infections with multiple serotypes do not result in a different clinical outcome compared to mono-infections. Published online by Cambridge University.

68. Dayarathna S, Jeewandara C, Gomes L, Somathilaka G, Jayathilaka D, Vimalachandran V, Wiojewickrama A, Narangoda E, Idampitiya D, Ogg GS, Malavige GN. (2020) Similarities and differences between the 'cytokine storm' in acute dengue and COVID-19. Scientific Reports vol 10, article number: 19839.

68a. Bicudo N, Bicudo E, Costa JD, Porto Castro JAL, Barcelos Bara G. (2020) Co-infection of SARS-CoV-2 and dengue virus: a clinical challenge. Braz J Infect Dis. 24(5);452-454.

69. Owen JA, Punt J, Stranford SA, Jones PP. (2009) Kuby Immunology. 7th ed., New York: W. H.Freeman and Company. 105-138.

70. Thisyakorn U, Nimmannitya S, Ningsanond V, Soogarun S. (1984) Atypical lymphocyte in dengue hemorrhagic fever: its value in diagnosis. Southeast Asian J Trop Med Public Health. 15:32-36.

71. Ralapanawa U, Alawattegama ATM, Gunrathne M, Tennakoon S, Kularatne SAM, Jayalath T. (2018) Value of peripheral blood count for dengue severity prediction. BMC Res Notes. 11:400415.

72. Ferede G, Tiruneh M, Abate E, Wondimeneh Y, Gadisa G, Howe r, Aseffa A, Tessema B. (2018) A study of clinical, hematological, and biochemical profiles of patients with dengue viral infections in Northwest Ethiopia: implications for patient management. BMC Infect Dis. 18:616-629.

73. Hassan J, Borhany M, Abid M, Zaidi U, Fatima N, Shamsi T. (2020) Coagulation abnormalities in dengue and dengue hemorrhagic fever patients. Transfus Med. 30:46-50.

74. Phuong HL, Thai KT, Nga TT, Giao PT, Hung le Q, Binh TQ, Nam NM, Groen J, de Vries P.(2009) Detection of dengue nonstructural 1 (NS1) protein in Vietnamese patients with fever.DiagnMicrobiolInfectDis63:372-378.

74a.Testing Guidance/Dengue/CDC. WWW.cdc.gov/dengue/healthcare providers/testing- guidance 2020.01.24.

75. Hottz ED, Oliveira MF, Nunes PCG, Nogueira FMR, Valls-deSouza R, Da Polan AT, Weyrich AS, Zimmerman GA, Bozza PT, Bozza FA. (2013) Dengue induces platelet activation, mitochondrial dysfunction and cell death through mechanisms that involve DC-SIGN and caspases. Journal Thromb Haemost. 11:951-962.

76. Lin C.-F, Wan S.-W, Cheng H.-J, Lei H.-Y, Lin Y.-S. (2006) Autoimmune pathogenesis in dengue virus infection. Viral Immunology. 19:127-132.

77. Srichaikul T, Nimmannmitya S. (2000) Haematology in dengue and dengue haemorrhagic fever. Bailliere's Best Practice and research in Clinical Haematology. 13:261-276.

78. Chaudhary R, Khetan D, Sinha S, Sinha P, Sonker P, Pandey P, Sekhar Das S, Agarwal P, Ray V. (2006) Transfusion support to Dengue patients in a hospital based blood transfusion service in north India. Transfus and Apheresis Science. 35:239-244.

79. Lye DC, Lee VJ, Sun Y, Leo YS. (2009) Lack of efficacy of prophylactic platelet transfusion for severe thrombocytopenia in adults with acute uncomplicated dengue infection. Clin Infect Dis. 48:1262-1265.

80. Pallavi P, Ganesh CK, Jayashree K, Manjunath GV. (2011) Unfurling the rationale use ofplatelet transfusion in dengue fever. Indian J Hematol Blood Transfus. 27:70-74.

81. Makroo RN, Raina V, Kumar P, Kanth RK. (2007) Role of platelet transfusion in the management of dengue patients in a tertiary care hospital. Asian J Transfus Sci. 1:4-7.

82. Lum LCS, Abdel-Latif MEA, Goh AYT, Chan PWK, Lam SK. (2003) Preventive transfusion in dengue shock syndrome - is it necessary? J Pediat. 143:682-684.

83. Wills BA, Oraqui EE, Stephens AC, Daramola OA, Dung NM, Loan HT, Chau NV, Chambers M, Stepniewska K, Farrar JJ. (2002) Coagulation abnormalities in dengue hemorrhagic fever: serial investigations in 167 Vietnamese children with dengue shock syndrome. Clin Infect Dis. 35:277-285.

84. Mcbride A, Mehta P, Rivino L, Ramanan AV, Yacoub S. (2021) Targeting hyperinflammation in infection: can we harness the COVID-19 therapeutics momentum to end the dengue drugs drought? Lancet Microbes.

85. Garcia G, Gonzalez N, Perez AB, Siera B, Aguirre E, Rizo D, Izquierdo A, Sanchez L, Diaz D, Lezcay M, Pacheco B, Hirayama K, Guzman MG. (2011) Long-term persistence of clinicalsymptoms in dengue-infected persons and its association with immunological disorders. Int J Infect Dis. 15:pages e38-e43.

86. Sampath P. (2015) When do dengue causing mosquitoes bite? / the HealthSite.comUpdated.

87. Jansen CC, Beebe NW. (2010) The dengue vector Aedes aegypti : what comes next? Microbes Infect. 12:272-279.

88. Mosquito life cycle - CDC.

89. Gould EA, Higgs S. (2009) Impact of climate change and other factors on emerging arbovirus diseases. Trans R Soc Trop Med Hyg. 103:109-121.

90. Barrera R, Amador M, Diaz A, Smith J, Munoz-Jordan JL, Rosario Y.(2008) Unusual productivity of Aedes aegypti in septic tanks and its implications for dengue control. Med Vet Entomol. 22:82-89.

91. Aedes aegypti - Wikipedia.

92. WHO (2019) / Dengue/Severe dengue frequently asked questions.

93. Hastings C. (2017) Mosquitoes more likely to transmit dengue virus in hot weather. 
94. Turell MJ, Dohm DJ, Sardelis MR, Oguinn ML, Andreadis TG, Blow JA. (2005) An update on the potential of north American mosquitoes (diptera, Culicidae) to transmit West Nile virus. J Med Entomol. 42:57-62.

95. How high can a dengue mosquito fly? - Quora.

96. Dengue Fever. Frequently Asked Questions (FAQ) Hawaii State Department of Health: (2016).

96a. Brady O, Wilder-Smith A. (2021) What is the impact of lockdowns on dengue? Current Inf Dis Reports. Published: 2021 Jan 2021.
97. "Sanofi's dengue vaccine approved in 11 countries". Reuters. (2016).

98. East S. (2016). "World first dengue fever vaccine launched in the Philippine". CNN.

99. Timeline: The Dengvaxia controversy - CNN Philippines.

100. Doucleff M. (2019) Dengue vaccine controversy in the Philippines.

101. Su S, Du L, Jiang S. (2021) Learning from the past: development of safe and effective COVID-19 vaccines. Nature Reviews Microbiology. 19:211-219.
Ready to submit your research? Choose Auctores and benefit from:

* fast, convenient online submission

* rigorous peer review by experienced research in your field

* rapid publication on acceptance

* authors retain copyrights

* unique DOI for all articles

* immediate, unrestricted online access

At Auctores, research is always in progress.

Learn more www.auctoresonline.org/journals/clinical-research-andclinical-trials 